\title{
Awareness, Knowledge, and Perceptions of Biosimilars Among Specialty Physicians
}

\author{
Hillel Cohen · Donna Beydoun · David Chien • Tracy Lessor • \\ Dorothy McCabe · Michael Muenzberg • Robert Popovian • \\ Jonathan Uy
}

Received: September 16, 2016 / Published online: October 31, 2016

(c) The Author(s) 2016. This article is published with open access at Springerlink.com

\section{ABSTRACT}

Introduction: The Biosimilars Forum conducted a survey through an independent organization from November 20, 2015 to January 4, 2016 in order to assess current levels of awareness, knowledge, and perceptions of biosimilars among US specialty physicians who already prescribe biologics. The survey was intended to provide a baseline level of knowledge about biosimilars and will be

Enhanced content To view enhanced content for this article go to http://www.medengine.com/Redeem/ F117F0605EC06625.

Electronic supplementary material The online version of this article (doi:10.1007/s12325-016-0431-5) contains supplementary material, which is available to authorized users.

H. Cohen $(\varangle) \cdot J$. Uy

Sandoz Inc., Princeton, NJ, USA

e-mail: hillel.cohen@sandoz.com

D. Beydoun

Merck \& Co., Inc., Kenilworth, NJ, USA

D. Chien

Amgen, Thousand Oaks, CA, USA

T. Lessor

Feinstein Kean Healthcare, New York, NY, USA repeated in 2-3 years in order to monitor trends over time.

Methods: A 19-question survey was created by the Biosimilars Forum and was administered by an independent third party.

Results: Responses were obtained from 1201 US physicians across specialties that are high prescribers of biologics, including dermatologists, gastroenterologists, hematologistoncologists, medical oncologists, nephrologists, and rheumatologists.

Conclusions: The results of this survey highlight a significant need for evidence-based education about biosimilars for physicians across specialties. Five major knowledge gaps were identified: defining biologics, biosimilars, and biosimilarity; understanding the approval process and the use of "totality of evidence" to

\author{
D. McCabe \\ Boehringer Ingelheim Pharmaceuticals, Inc., \\ Ridgefield, CT, USA \\ M. Muenzberg \\ Ares Trading SA, Aubonne, Switzerland \\ R. Popovian \\ Pfizer Inc., New York, NY, USA
}


evaluate biosimilars; understanding that the safety and immunogenicity of a biosimilar are comparable to the originator biologic; understanding the rationale for extrapolation of indications; and defining interchangeability and the related rules regarding pharmacy-level substitution.

Funding: Biosimilars Forum.

Keywords: Biologic; Biosimilar; Biosimilarity; Extrapolation; Immunogenicity; Interchangeability; Originator biologic

\section{INTRODUCTION}

Biosimilars are biological products that are approved on the basis of multiple comparability steps that demonstrate high similarity to an already FDA-approved originator biologic, and that have demonstrated no clinically meaningful differences in quality, safety, and efficacy. As of August 2016, three biosimilars have been approved by the FDA, of which one has already been marketed since September 2015. Approximately 60 other biosimilars are in clinical development in the US [1-4].

Although biosimilars are relatively new to the United States (US) market, they have been safely utilized in Europe (since 2006), Australia, Canada, Japan, and several other countries worldwide, resulting in more than 400 million patient-days of exposure to more than 20 biosimilars for numerous molecules, including recombinant human growth hormone (rhGH), erythropoietin, filgrastim, insulin, follitropin, infliximab, and etanercept [5-7]. As more biosimilars enter the US market over the coming years, they are expected to expand patient access to life-saving medications for difficult-to-treat diseases, such as cancer, anemia, and endocrine and autoimmune disorders (e.g., multiple sclerosis, rheumatoid arthritis, psoriasis, and inflammatory bowel disease) because they will offer an alternative to existing biologics for Medicare, Medicaid, and the private sector [8].

Several of the leading biosimilar sponsors created the Biosimilars Forum in 2015 to advance biosimilars in the US with the intent of expanding access and availability of biological medicines to improve health care [9]. The Biosimilars Forum provides evidence-based information to inform and support public policies that encourage awareness, access, and adoption of biosimilars. Current members include: Allergan, Amgen, Boehringer-Ingelheim, Coherus, EMD-Serono, Merck, Pfizer, Samsung Bioepis, Sandoz, and Teva.

When generic drugs first became available in the US in the 1980s, physicians required a clear understanding of this new class of drugs before they were comfortable prescribing them to patients [10]. Similarly, it is expected that physicians will also require an in-depth understanding of biosimilars before they feel comfortable offering these new treatment options to their patients. In order to assess current levels of awareness, knowledge, and perceptions of biosimilars among specialty physicians who already prescribe biologics, the Biosimilars Forum conducted a survey through an independent organization from November 20, 2015 to January 4,2016 . The survey was intended to provide a baseline level of knowledge among specialty physicians. A similar survey will be conducted in 2-3 years time with the same design in order to monitor trends in the awareness, knowledge, and perceptions of biosimilars over time. 


\section{METHODS}

A 19-question survey was created by the Biosimilars Forum, and a third-party organization, SERMO (a global social network organization for physicians), was contracted to conduct the survey. An attempt was made to word all questions in a neutral manner. Respondents were not informed that pharmaceutical companies had created the questionnaire because it was felt that knowledge of this fact might bias the responses, although it was prospectively planned to disclose this fact at the time of publication. Responses were obtained from 1201 US physicians across specialties that are high prescribers of biologics, including dermatologists, gastroenterologists, hematologist-oncologists, medical oncologists, nephrologists, and rheumatologists. The profile of SERMO US physician members closely mirrors that of all US physicians (as measured by the American Medical Association (AMA)) [11]. The anonymous respondents represented a cross-section of years of experience primarily between 6 and 30 years, although the largest portion of respondents was in practice for 11-20 years (32.8\%). Survey respondents who did not prescribe biologics were excluded from the survey, and were not counted among the 1201 participants.

The survey examined a range of topics important to establish the foundation of biosimilars in the US, including: physician understanding of biosimilars and perceptions of critical quality attributes; safety and efficacy; biosimilarity; extrapolation; interchangeability; approval requirements and processes; existing and pending regulations regarding use; and value to patients. Ongoing policy issues that were not yet resolved by the US Food and Drug Administration (FDA) were explicitly excluded, although questions were posed about the concept of interchangeability since that concept can impact the use of biosimilar products in the US. The survey was also designed to gather information about physician intent to use biosimilars in their practice, the impact of expanded access to biologics and biosimilars on patient costs, and greater adherence with treatment regimens. The survey results are limited to the specialty groups surveyed and cannot be extrapolated to other physician groups or healthcare professionals.

There are several limitations to the survey. At the time of the survey, only one biosimilar was approved and marketed in the US as a supportive treatment for a hematology-oncology indication. This product was first available in the US in September 2015, only 3-4 months before the survey was conducted. As a result, there was no immediate need for physicians in the other specialties surveyed to be knowledgeable about biosimilars. The survey represents a snap shot in time; therefore, it may not reflect the awareness, knowledge or perceptions of biosimilars by specialty physicians today. Biosimilars have since received significant press coverage, and several healthcare practitioner societies, patient advocacy groups, companies, and trade associations (including the Biosimilars Forum) have initiated biosimilar educational activities geared toward healthcare professionals after the survey was completed.

This article does not contain any new studies with human or animal subjects performed by any of the authors.

\section{RESULTS AND DISCUSSION}

\section{General Awareness of Biologics and Biosimilars}

Overall, most physicians are aware of which drugs used within their specialties are 


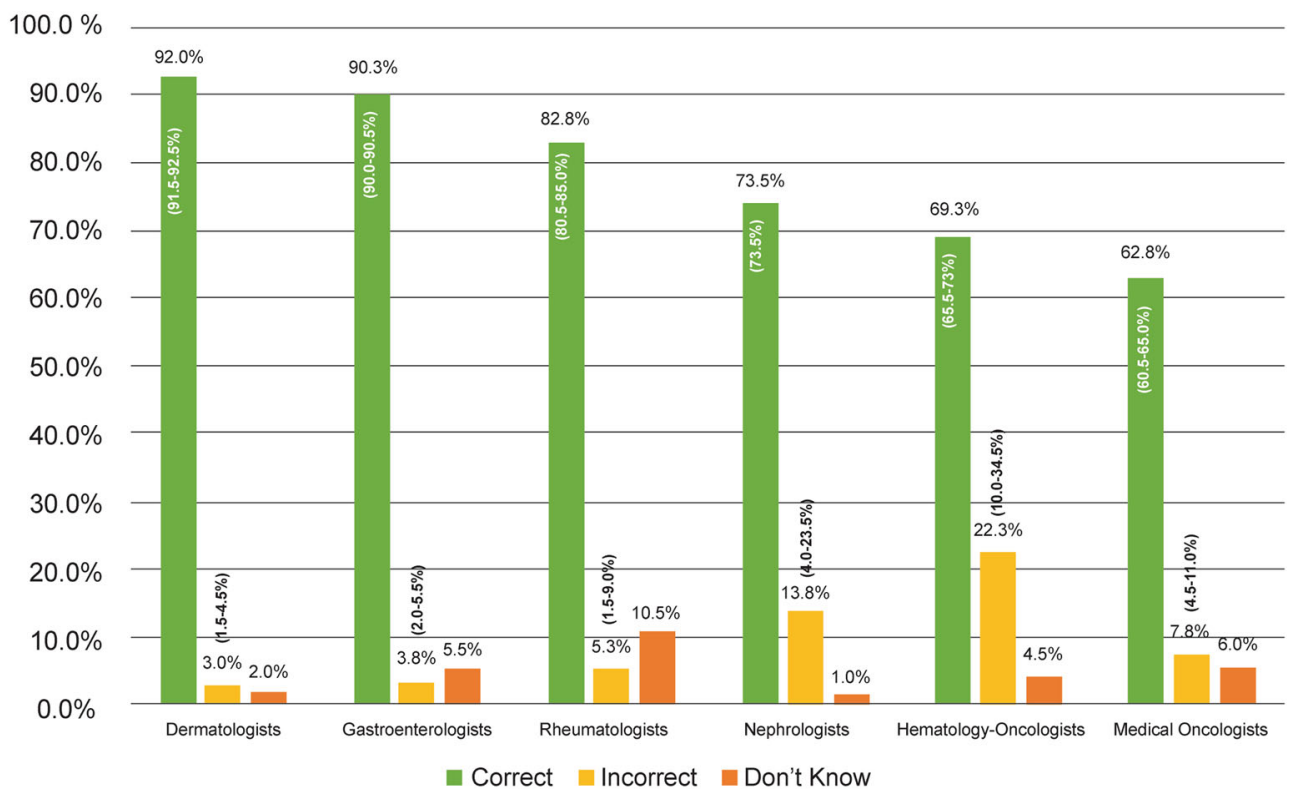

Fig. 1 Physicians were provided with a list of drugs used by their specialty, only some of which were biological drugs. They were asked to identify whether each drug was a

biologics; however, there was a sizeable minority that did not know this information (Fig. 1). Some physicians mistookchemical drugs for biologics and many selected "none of the above," which indicated that they did not recognize any of the suggested therapies as biologics. These data reflect a lack of understanding of what defines a biologic, which was surprising since all physicians included in the survey responded that they prescribe biologic drugs. If physicians do not know that a given drug is a biologic, it will create an educational challenge to explain that, after patent expiry, copies of these therapies will be marketed as biosimilars instead of as generic drugs.

Although the vast majority of respondents across all specialties have heard about biosimilars (Fig. S1 in Supplementary Materials), their actual knowledge of the fundamentals of biosimilars, as demonstrated in greater detail below, was low. For example, a biologic and were also given the option of selecting "None of the above" or "I do not know". (Bars represent the mean, with ranges provided vertically)

sizable minority was unaware that a biosimilar was available in the US (Fig. 2).

Most respondents (75\%) appear to trust FDA approval decisions; however, they will still want additional information when making treatment decisions (Fig. S2 in Supplementary Materials). A small group of respondents (13\%), predominantly dermatologists and rheumatologists, will not solely trust the FDA's assessments and decision to approve the biosimilar and will seek more information. Presumably, these physicians will decide which medications to use based on their own assessments. The survey did not probe further into how those decisions would be made.

\section{Understanding and Perceptions of Key Concepts Related to Biosimilars}

Only half of respondents are knowledgeable of the concept of totality of evidence, which is a new data evaluation paradigm used to assess a 


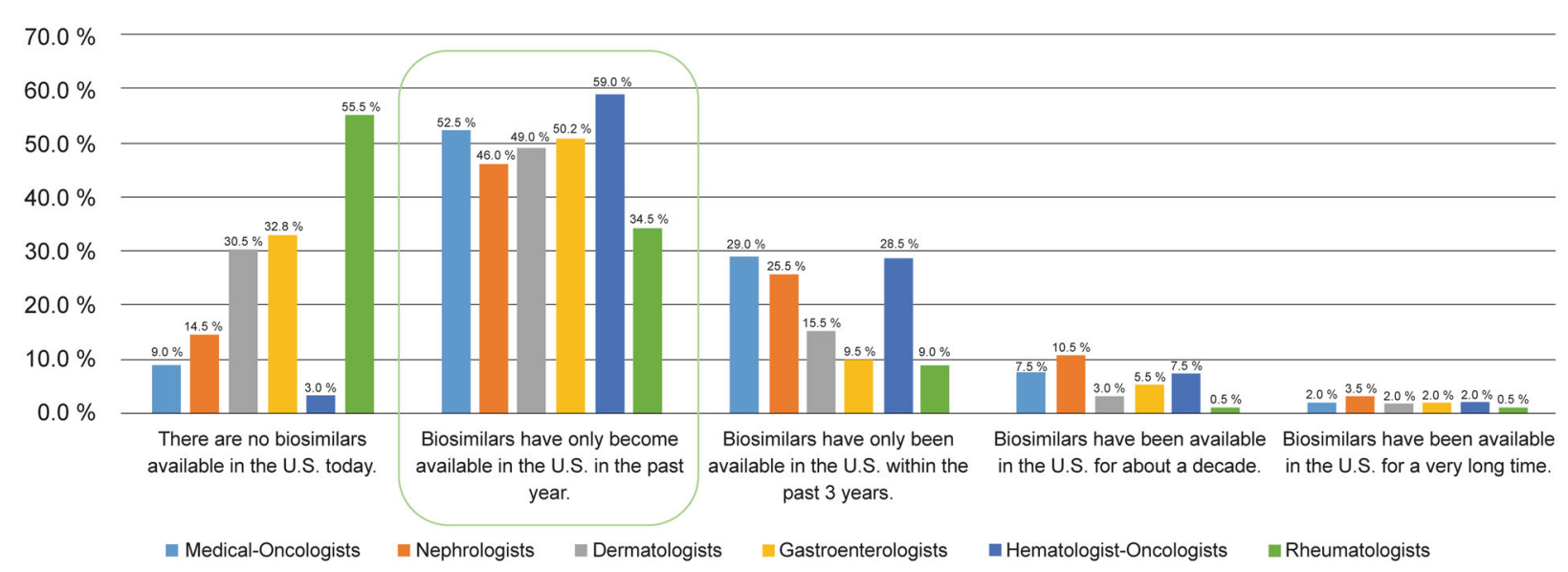

Fig. 2 Respondents were asked how long have biosimilars been available in the US. The correct answer is encircled

biosimilar (Fig. 3) [12]. This insight is not surprising because innovator drug development is typically not based on analytical data and has always included clinical data for all indications. Physicians have been taught to expect as such when assessing new drugs.
One fundamental premise of biosimilars is that a product will be clinically evaluated in one or more indications of use, and the FDA may 'extrapolate' the totality of data to approve the biosimilar for use with other indications for which the originator biologic is approved. While only $12 \%$ of respondents surveyed are

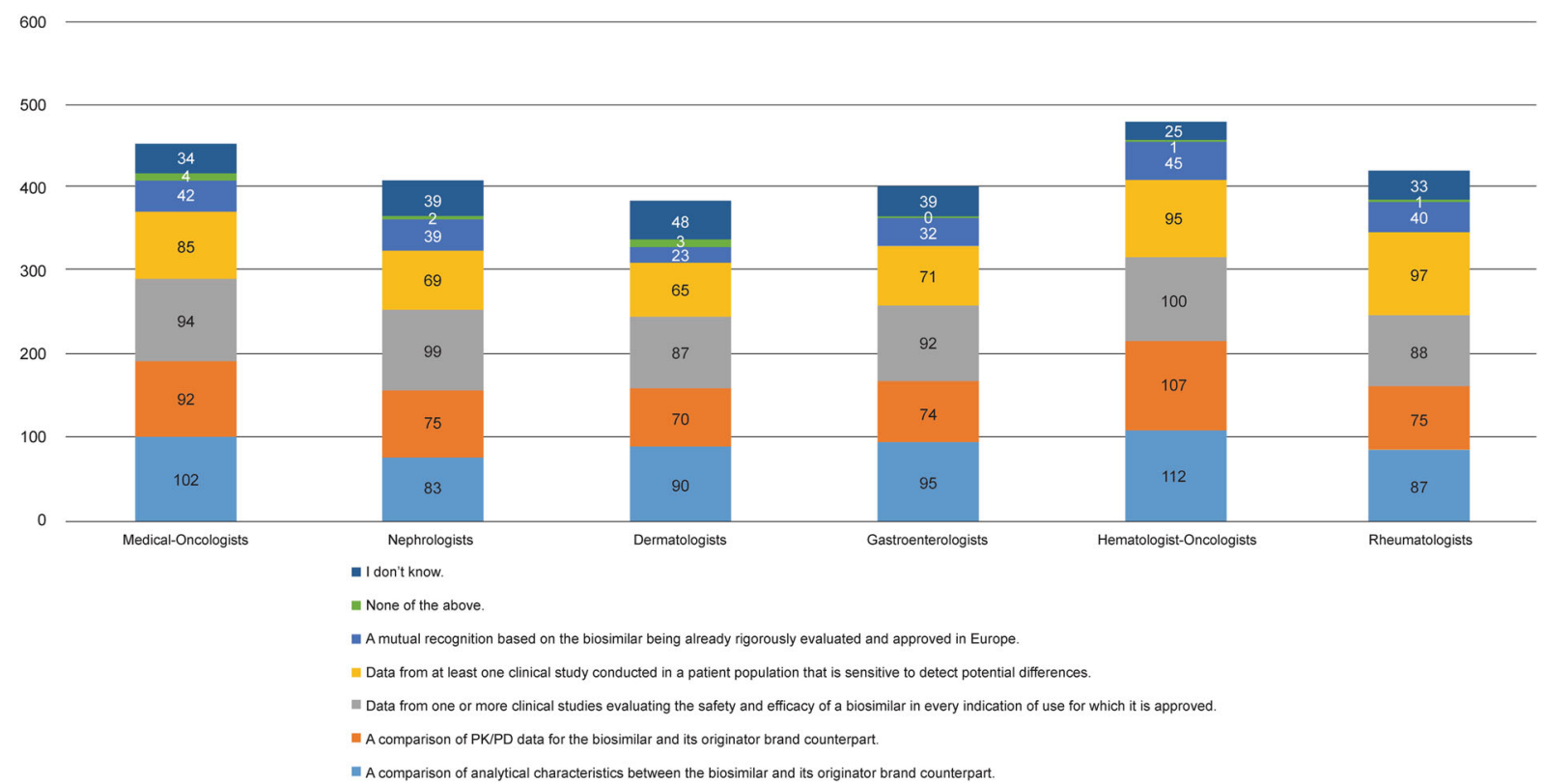

Fig. 3 Respondents were asked what criteria they believe FDA will use to approve a biosimilar. There are three correct responses to this question: "Data from at least one clinical study in a patient population that is sensitive to detect differences;" "A comparison of PK/PD data for the biosimilar and its originator counterpart;" and "A comparison of analytical characteristics between the biosimilar and its originator brand counterpart" 
comfortable with the concept of extrapolation (Fig. S3 in Supplementary Materials), separate questions that assessed details of extrapolation reveal that most physicians are not familiar with the concept. This lack of knowledge was further highlighted at a US Advisory Committee meeting held on July 12-13, 2016, [13] whereby the panelists became more accepting of the concept after it was explained that extrapolation was based on totality of evidence data from the originator biologic molecule to the biosimilar molecule and not from the clinical aspects of one indication to another indication.

Almost $60 \%$ of respondents correctly understood that to be approved as "interchangeable," a biosimilar must be shown to be safe and effective for back-and-forth switching with no negative impacts to safety or efficacy (Fig. S4a in Supplementary Materials). However, there is a lack of awareness or misinformation about the term 'interchangeable' (Fig. S4b-e). Overall, one-third of respondents believe that the term means that approval of a biosimilar implies interchangeability with the originator biologic
(Fig. S4b). In fact, an additional category was created within the US regulatory pathway for an interchangeable product. As of the time of writing of this article, the exact nature of the additional information that will be needed has not yet been defined, but is thought to include additional clinical data beyond that provided to establish biosimilarity. An overwhelming 80\% of the respondents were not aware that interchangeability would enable a pharmacist to switch between originator biologic and biosimilar, and vice versa (Fig. S4c).

\section{Perceptions of Safety and Efficacy}

More than half of respondents are aware that biosimilars must be comparable in safety and efficacy to the originator biologic, although that leaves a sizeable minority who are uncertain about these important approval criteria (Fig. 4). Physicians who are uncertain of this foundational fact are more likely to have reservations and may be cautious in adopting biosimilars.

Nonetheless, a large percentage of respondents are unsure or concerned about

\begin{tabular}{|l|l|l|l|l|l|l|}
\hline & Medical-Oncologists & Nephrologists & Dermatologists & Gastroenterologists & $\begin{array}{l}\text { Hematologist- } \\
\text { Oncologists }\end{array}$ & Rheumatologists \\
\hline $\begin{array}{l}\text { A. The biosimilar will } \\
\text { have equivalent } \\
\text { efficacy as its } \\
\text { originator brand } \\
\text { counterpart. }\end{array}$ & $67.5 \%$ & $67.5 \%$ & $52.0 \%$ & $59.2 \%$ & $69.0 \%$ & $58.5 \%$ \\
\hline $\begin{array}{l}\text { B. The biosimilar will } \\
\text { be at least as safe as } \\
\text { its originator brand } \\
\text { counterpart. }\end{array}$ & $66.5 \%$ & $53.5 \%$ & $48.0 \%$ & $56.7 \%$ & $62.5 \%$ & $56.0 \%$ \\
\hline $\begin{array}{l}\text { C. A pharmacist will be } \\
\text { allowed to substitute } \\
\text { a biosimilar for the } \\
\text { originator brand }\end{array}$ & $18.5 \%$ & $22.0 \%$ & $28.0 \%$ & $14.9 \%$ & $17.5 \%$ & $22.0 \%$ \\
counterpart without \\
asking the prescriber.
\end{tabular}

Fig. 4 Respondents were asked which of the following statements are true when the FDA approves a biosimilar. Choices $A$ and $B$ are correct 


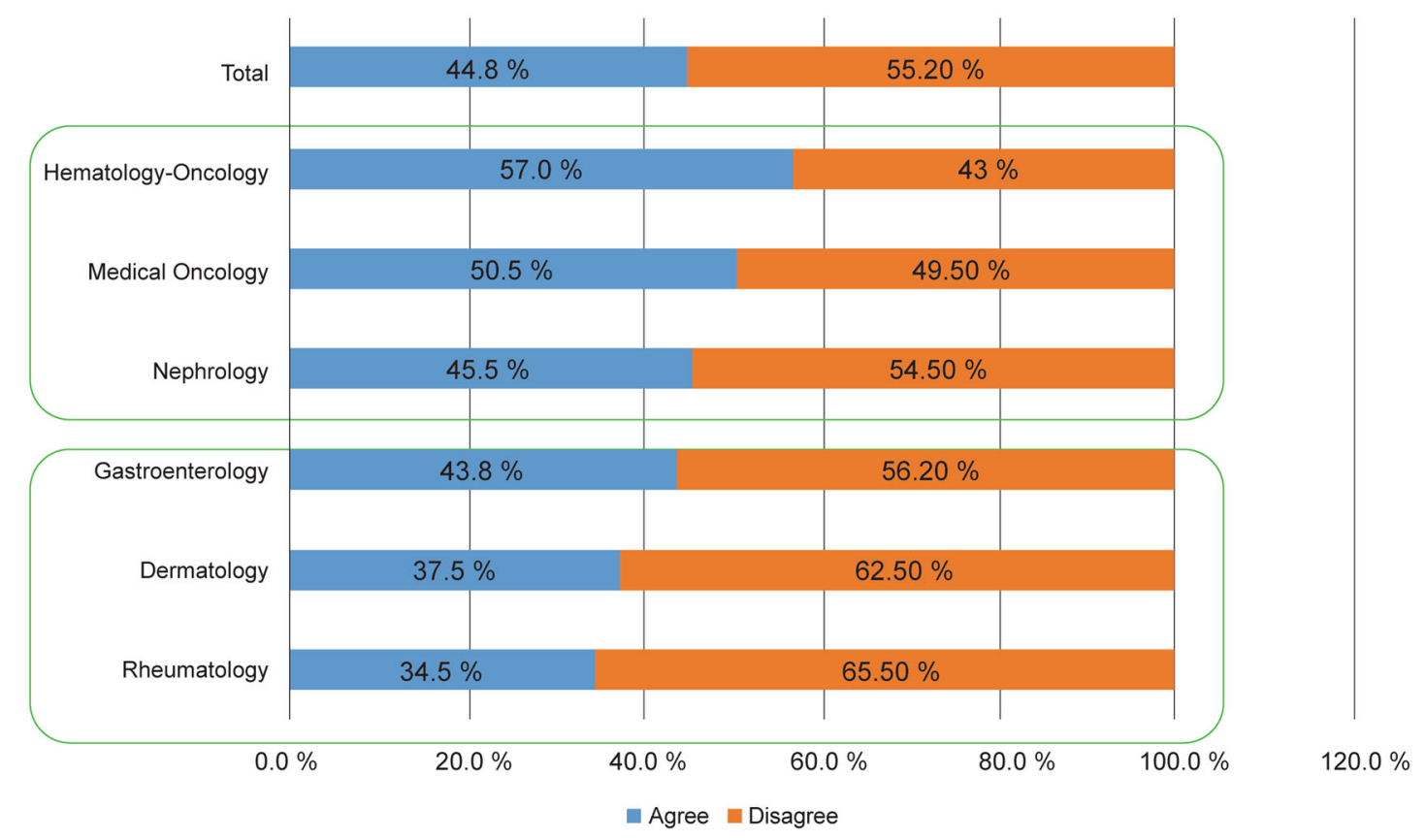

Fig. 5 Respondents were asked if they believe biosimilars will be safe and appropriate for use in naïve and existing patients

the safety of biosimilar medicines (Fig. 5), although the FDA can only approve a biosimilar if the agency is convinced that the safety profile is comparable to that of the originator biologic. This misconception could simply be due to a lack of knowledge, although the higher levels of uncertainty among rheumatologists compared to other specialties suggests that this concern may be caused, at least in part, by coordinated activities that raise questions about biosimilars and the biosimilar pathway, as biosimilars are being developed for several leading rheumatology products marketed in the US.

About half of respondents across all specialties specified that they wanted to have access to data directly evaluating the safety of switching patient populations from the originator biologic to its biosimilar (Fig. 6). This highlights a potential concern of many physicians that the very act of switching may be dangerous because of concerns that the biosimilars may not be structurally identical to their reference product. It is likely that some physicians are unaware of two factors: (1) the primary sequence of a biosimilar must be identical to the reference product, and (2) that the quality attributes of all biologics (including both originator biologics and biosimilars) often vary from batch to batch within specified limitations, and that this variability has not led to safety concerns [14]. The critical quality attributes of batches of biosimilars must also be within the very same limits (pending FDA issuance of a guidance on statistical considerations for the analysis of analytic similarity). In addition, while not specified in the Biologics Price Competition Act of 2009 (BPCIA) [15] or in US guidance documents, as of September 2016, all biosimilar products approved by the FDA have incorporated at least one switch from originator biologic to biosimilar into their biosimilar clinical development programs. These important factors must be better communicated to physicians. 


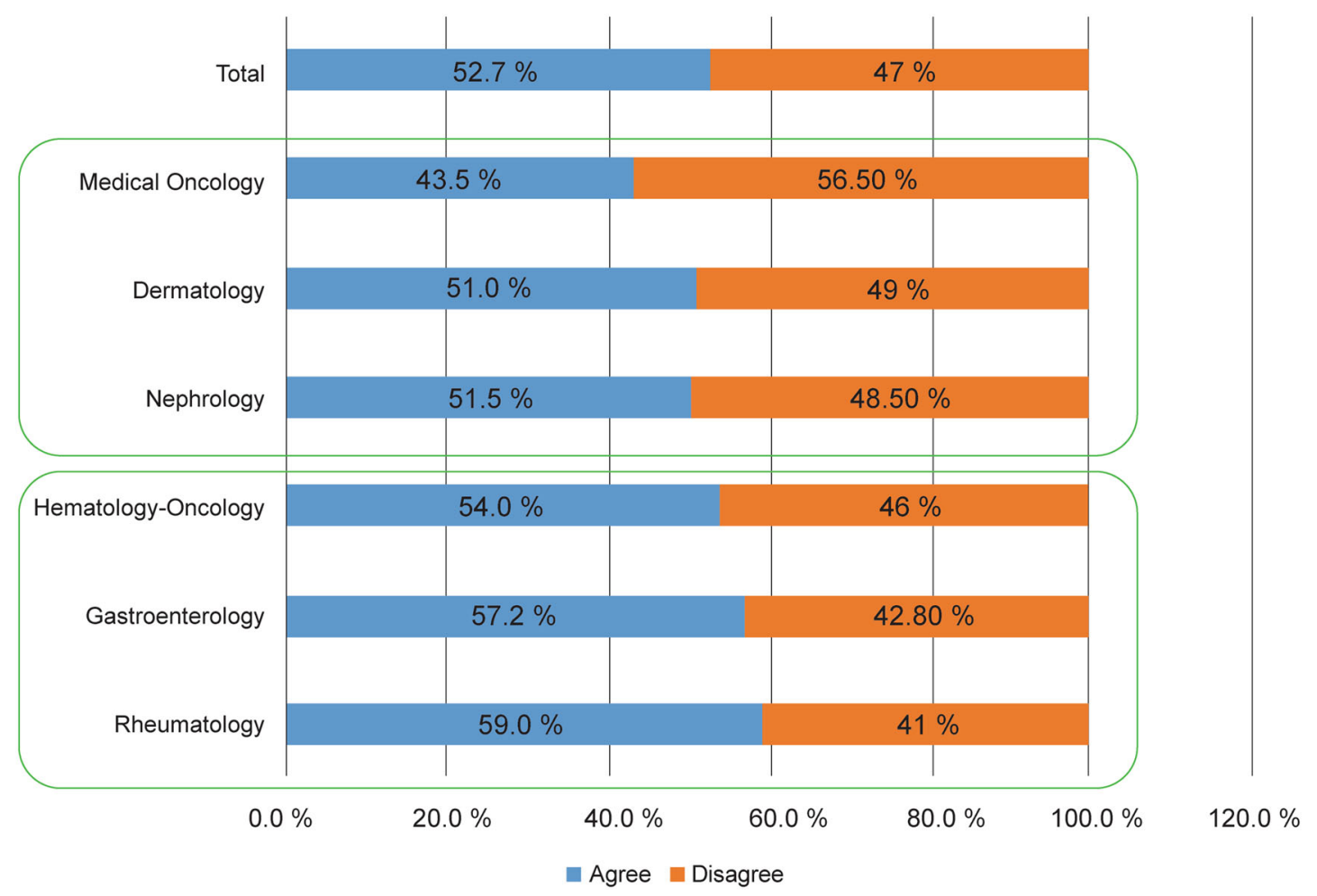

Fig. 6 Respondents were asked if it would be essential for doctors to have data directly evaluating the safety of switching patients from an originator biologic to its biosimilar

More than one-third of respondents believe that abbreviated approval translates to a greater safety risk (Fig. 7), which may reveal a basic misunderstanding that the "abbreviated" program refers to less supportive data. In fact, the analytical data requirement is much greater and forms the basis for the totality of evidence supporting biosimilarity. The "abbreviated" portion refers only to a requirement for fewer and smaller efficacy and safety studies because the purpose of biosimilar clinical studies is to confirm high similarity to the originator biologic and not to re-establish the safety and efficacy profile that was already established by the originator biologic. Of the specialties, dermatologists and rheumatologists expressed significantly higher concerns at $43 \%$ and $48 \%$, respectively.

Finally, the majority of physicians (85\%) appreciate that, as is true for all biologics, the immunogenicity profile of a biosimilar will not be completely known pre-approval (Fig. S5 in Supplementary Materials). To alleviate possible concerns about immunogenicity of a given biosimilar, it will be important to communicate the safety data that will be obtained from post-approval pharmacovigilance surveillance. It also may be useful to better communicate the safety data obtained with use of biosimilars in Europe, where there have been more than 400 million patient-days of experience in which no new immunogenicity concerns have been observed [5].

\section{Preferred Information Sources}

Peer-reviewed literature is by far the most trusted and preferred information source for biosimilars among physicians (82\%; Fig. S6 in Supplementary Materials). The top trusted 


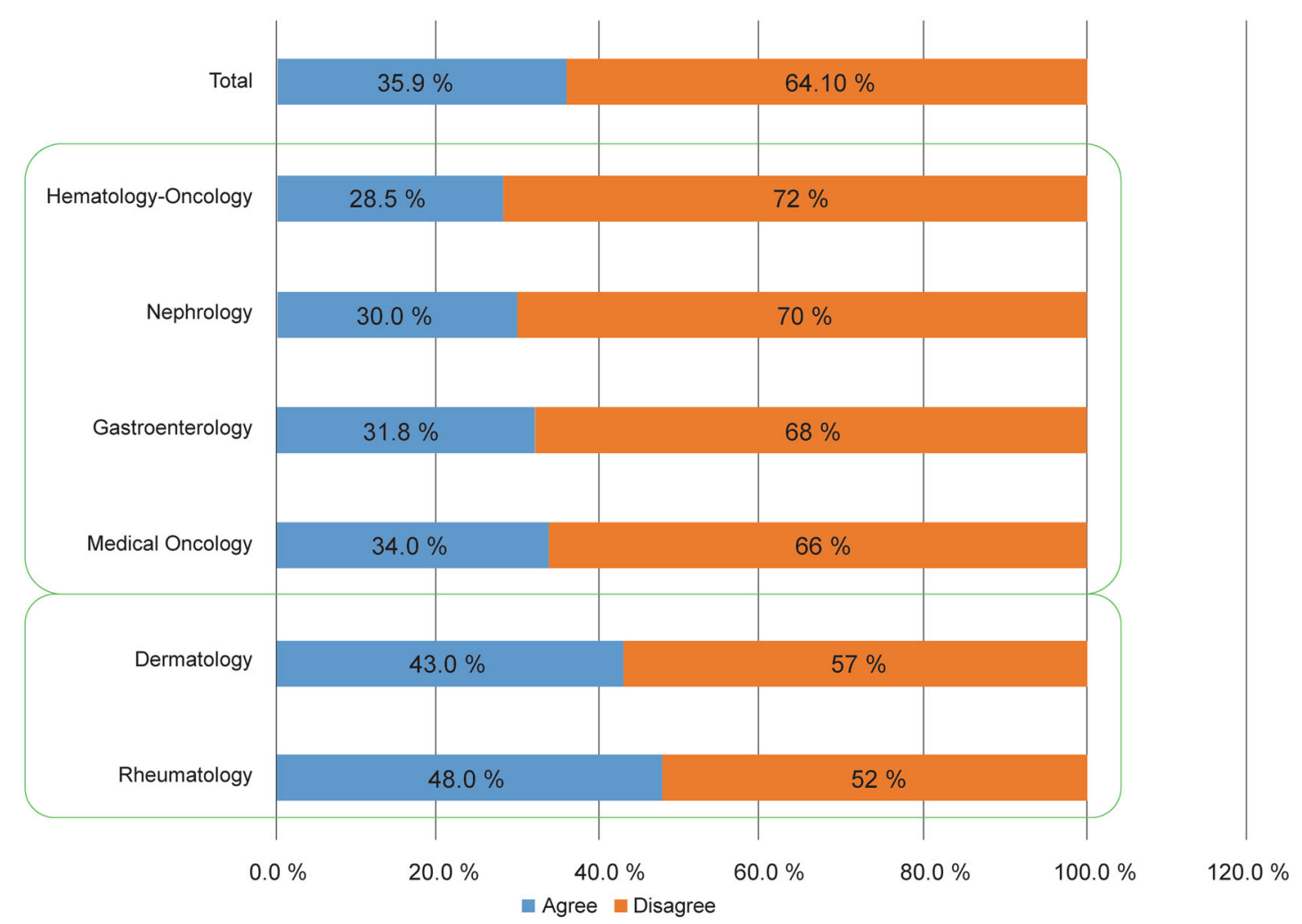

Fig. 7 Respondents were asked if they believe a biosimilar will be less safe than its originator biologic because it will be approved through an abbreviated pathway

information sources include scientific journals (88\%), FDA (73\%), and physician peers (64\%); however, dermatologists and rheumatologists indicated less trust in the FDA as an information source compared with other specialties at $64 \%$ and 58\%, respectively (Fig. S7 in Supplementary Materials). Physician trust in media was very low across all specialties $(<5 \%)$. Journals, physician peers, and congresses/symposia are the primary trusted information sources for current information on biosimilars across specialties.

\section{Physician Interests and Overall Thoughts}

Approximately $60 \%$ of respondents are concerned about patient compliance with originator biologics and/or access to treatment options (Fig. 8). A large majority of respondents believe that biosimilars will enable increased access and utilization, expand treatment options, and provide savings to the US healthcare system (Fig. S8a, b in Supplementary Materials). Although a large majority of respondents (91\%) are open to switching patients to a biosimilar (Fig. S9 in Supplementary Materials), the concerns noted above in several separate questions must be taken into account as they may impact uptake and utilization of biosimilars. Primarily, physicians are open to the concept of using biosimilars for their patients but would like to see the supportive data for their indication. They would also like to see switching data. When the FDA requires one-time switch data from originator biologic to biosimilar for chronic conditions, the switching data will be available but must be communicated. 


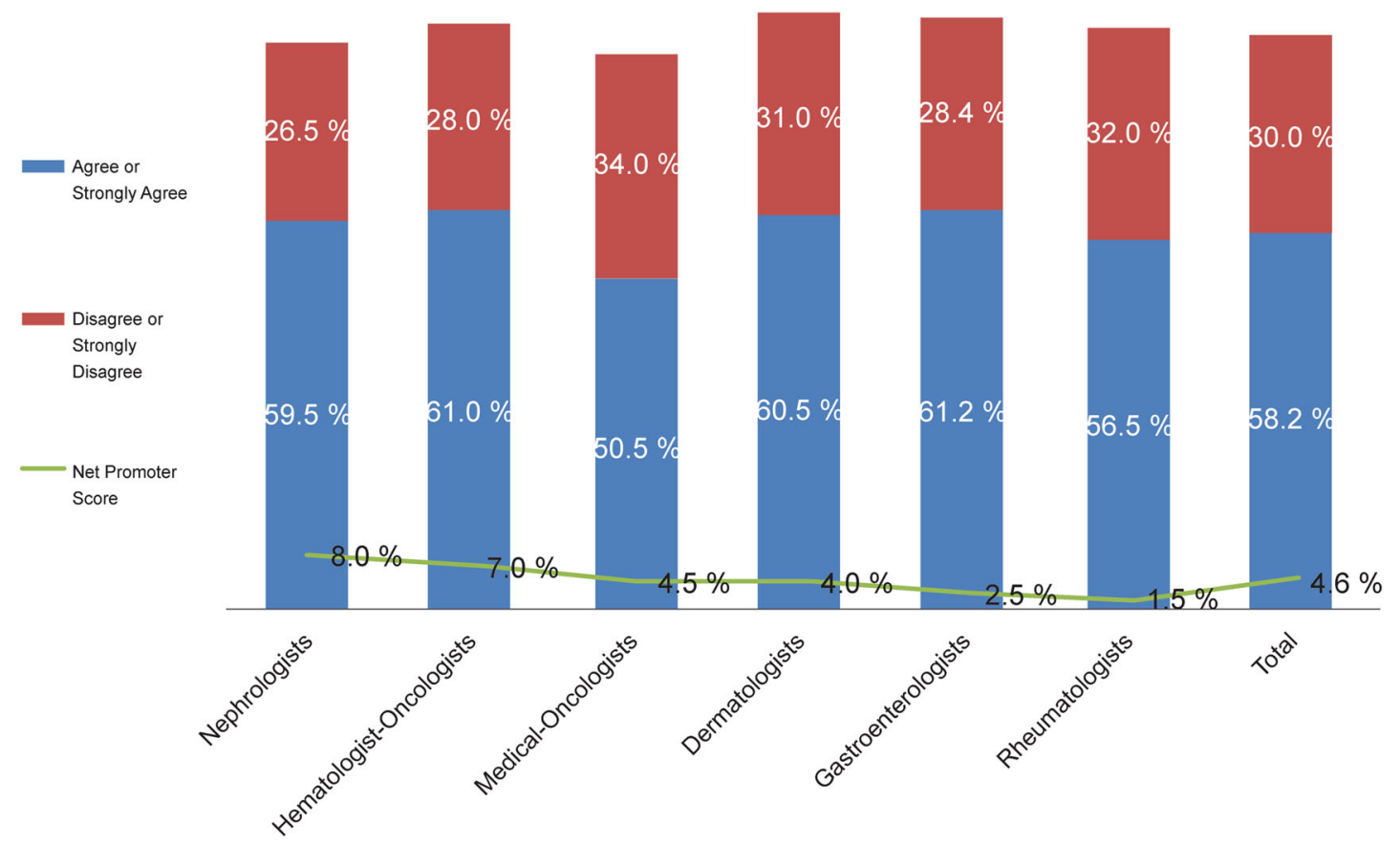

Fig. 8 Respondents were asked to rate their level of agreement with the following statement: "With originator biologic medicines, I have concerns about my patients' compliance and/or access to treatment options"

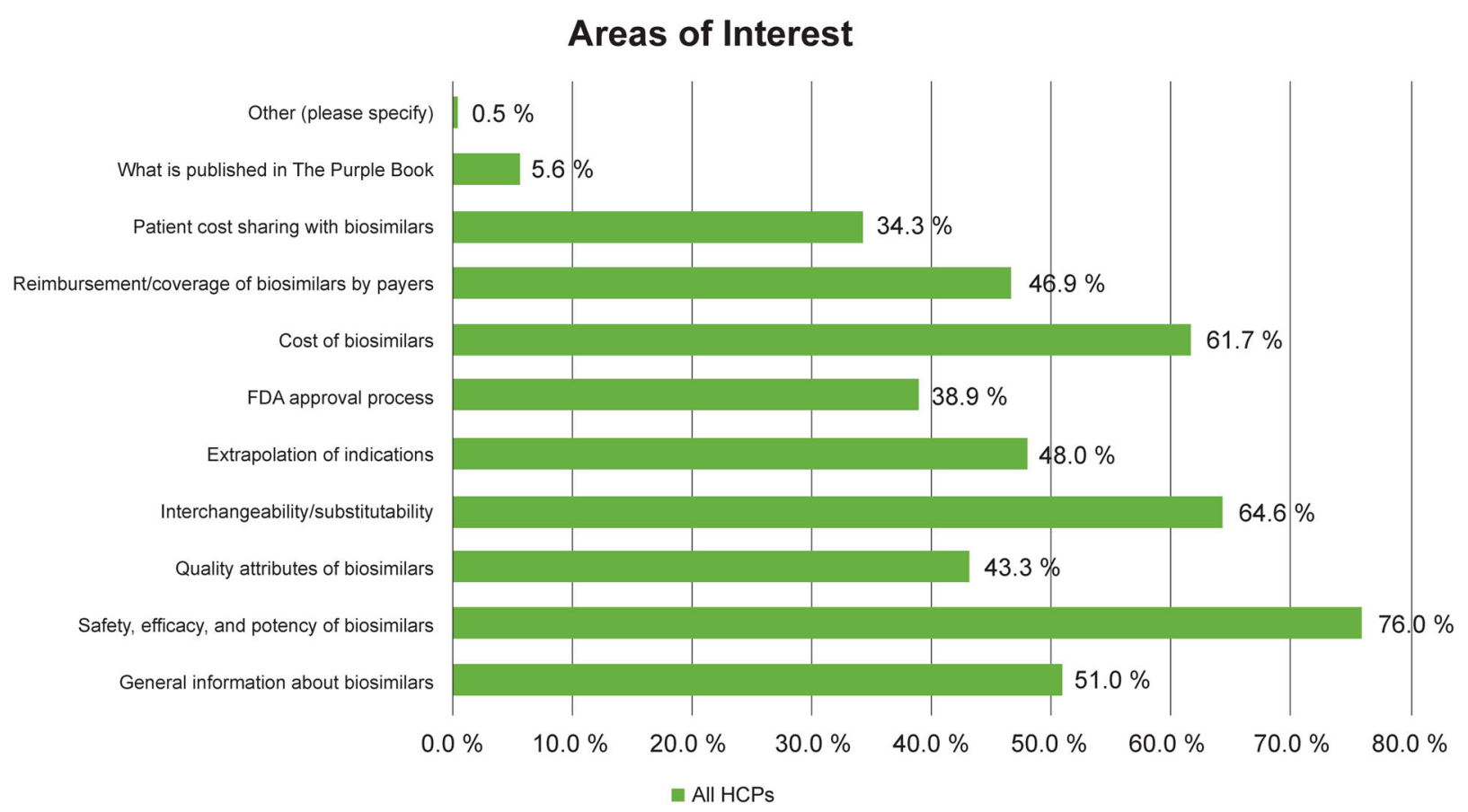

Fig. 9 Respondents were asked which biosimilars topics they were most interested in learning more about 
Finally, most physicians are interested in learning more about key biosimilar concepts, suggesting an openness to learn. Topics of interest to physicians included product attributes of safety and efficacy and key concepts of biosimilars (totality of evidence, extrapolation, interchangeability), as well as information on access and the economics of biosimilars (Fig. 9).

\section{CONCLUSION}

The results of this survey highlight a significant need for evidence-based education about biosimilars for physicians across specialties. Although the vast majority of physicians have heard about biosimilars, their actual knowledge of the fundamentals of biosimilars was low, as the portion of respondents answering correctly rarely surpassed $50 \%$ for questions that focused on key aspects of these therapies.

Five major knowledge gaps were identified: defining biologics, biosimilars and biosimilarity; understanding the approval process and the use of "totality of evidence" to evaluate biosimilars; understanding that the safety and immunogenicity of a biosimilars are comparable to the originator biologic; understanding the rationale for extrapolation of indications; and defining interchangeability and the related rules regarding pharmacy-level substitution. With respect to future educational efforts, peer-reviewed literature is by far the most trusted and preferred information source for biosimilars among specialty physicians.

Although physicians across specialties have generally positive attitudes toward biosimilars, dermatologists and rheumatologists appear to be less enthusiastic about biosimilars, particularly due to safety concerns. These physician groups may require more information from trusted sources to address their current concerns.
This survey provides a baseline of of the knowledge level of physicians about biosimilars. A similar survey will be repeated in 2-3 years time to monitor changes.

\section{Biosimilar Definitions [16]}

A BIOSIMILAR MEDICINE is a biologic that is highly similar to an FDA-approved biological medicine, known as an originator biologic. A biosimilar must be (1) highly similar to the originator biologic notwithstanding minor differences in clinically inactive components, and (2) have no clinically meaningful differences in safety or effectiveness compared to the originator biologic

\section{An INTERCHANGEABLE BIOLOGIC is a}

biosimilar that has been demonstrated to produce the same clinical result as its originator biologic in any given patient. In addition, for a product that is administered multiple times to an individual, the risk in terms of safety or diminished efficacy of alternating between use of the interchangeable biologic and its originator biologic is not greater than the risk of using the originator biologic alone. Designation of interchangeability requires additional supporting evidence, which will be further defined by the FDA

An interchangeable biologic may be substituted by a pharmacist for the originator biologic or vice versa without the intervention of the healthcare professional who wrote the prescription. State laws govern the substitution process, and communication to the healthcare provider who wrote the prescription may be required after the product is dispensed

EXTRAPOLATION is the process by which a biosimilar may be approved for one or more indications for which its reference biological product is licensed but for which there was no head-to-head clinical comparison. This approval is based on the extrapolation of the totality of data obtained with the biosimilar molecule in direct comparison to the originator biologic. Every indication for which extrapolation is sought must be scientifically justified 


\section{ACKNOWLEDGEMENTS}

The design, execution, analysis, and article processing charges were funded by the Biosimilars Forum, Washington, DC, USA. The founding members of the Biosimilars Forum represent the majority of companies with the most significant US biosimilars development portfolios, including: Allergan, Amgen, Boehringer Ingelheim, Coherus BioSciences, EMD Serono, Merck, Pfizer, Samsung Bioepis, Sandoz, and Teva. Amgen, Boehringer Ingelheim, EMD Serono, Merck, Pfizer and Sandoz were the Biosimilars Forum companies that contributed to this publication. All named authors meet the International Committee of Medical Journal Editors (ICMJE) criteria for authorship for this manuscript, take responsibility for the integrity of the work as a whole, and have given final approval to the version to be published. All authors had full access to all of the data in this study and take complete responsibility for the integrity of the data and accuracy of the data analysis.

Geoffrey Eich of Amgen Inc. provided assistance with survey design and data analysis. Melissa Glim, Monique LaRocque and Carey Pilato of Feinstein Kean Healthcare | Ogilvy provided assistance with survey design, data analysis, and editing.

Disclosures. Hillel Cohen is an employee of Sandoz Inc. and owns stock in the Novartis Corp.

Donna Beydoun is an employee and stockholder of Merck, Inc.

David Chien is an employee and stockholder of Amgen Inc.

Tracy Lessor is an employee of Feinstein Kean Healthcare. She does not own stock.

Robert Popovian is an employee and stockholder of Pfizer Inc.
Dorothy McCabe is an employee of Boehringer Ingelheim, and owns stock in Pfizer Inc.

Michael Muenzberg is an employee of Ares Trading S.A. He does not own stock.

Jonathan Uy is an employee of Sandoz Inc. and owns stock in the Novartis Corp.

Compliance with Ethics Guidelines. This article does not contain any new studies with human or animal subjects performed by any of the authors.

Open Access. This article is distributed under the terms of the Creative Commons Attribution-NonCommercial 4.0 International License (http://creativecommons.org/licenses/ by-nc/4.0/), which permits any noncommercial use, distribution, and reproduction in any medium, provided you give appropriate credit to the original author(s) and the source, provide a link to the Creative Commons license, and indicate if changes were made.

\section{REFERENCES}

1. US Food and Drug Administration. FDA approves first biosimilar product Zarxio. Retrieved from: http://www.fda.gov/newsevents/newsroom/press announcements/ucm 436648.htm. Accessed 6 Mar 2015.

2. US Food and Drug Administration. FDA approves Inflectra, a biosimilar to Remicade. Retrieved from: http://www.fda.gov/NewsEvents/Newsroom/Press Announcements/ucm 494227.htm. Accessed 5 Apr 2016.

3. US Food and Drug Administration. FDA approved Erelzi, a biosimilar to Enbrel. Retrieved from: http://www.fda.gov/NewsEvents/Newsroom/Press Announcements/ucm518639.htm. Accessed 30 Aug 2016.

4. Eastern Research Group, Inc. Review of biosimilar product applications: study of workload volume and full costs. Retrieved from: http://www.fda.gov/ downloads/ForIndustry/UserFees/BiosimilarUserFee ActBsUFA/UCM488846.pdf. Accessed 24 Feb 2016. 
5. IMS Health. The Impact of Biosimilar Competition. Retrieved from: http://ec.europa.eu/growth/tools-data bases/newsroom/cf/itemdetail.cfm?item_id $=8854$. Accessed 20 June 2016.

6. US Food and Drug Administration. FDA Oncologic Drugs Advisory Committee Meeting: ZARXIO ${ }^{\circledR}$ (filgrastim). Retrieved from: http://www.fda.gov/ downloads/AdvisoryCommittees/CommitteesMeet ingMaterials/Drugs/OncologicDrugsAdvisoryCom mittee/UCM428782.pdf. Accessed 7 Jan 2015.

7. Mielke J, Jilma B, Koenig F, Jones B. Clinical trials for authorized biosimilars in the European Union: a systematic review. Br J Clin Pharmacol. 2016. doi:10.1111/bcp.13076.

8. US Food and Drug Administration. Biosimilars: more treatment options are on the way. Retrieved from: http://www.fda.gov/ForConsumers/ ConsumerUpdates/ucm436399.htm. Accessed 7 Apr 2016.

9. Biosimilars Forum Homepage. Retrieved from: www.biosimilarsforum.org. Accessed 24 Feb 2016.

10. Berndt Ernst R, Aitken Murray L. Brand loyalty, generic entry and price competition in pharmaceuticals in the quarter century after the 1984 Waxman-Hatch legislation. Int J Econ Bus. 2011;18(2):177-201.

11. SERMO. SERMO polls. Retrieved from: http://www. sermo.com/polls. Accessed 15 Aug 2016.
12. US Department of Health and Human Services, Food and Drug Administration, Center for Drug Evaluation and Research (CDER), Center for Biologics Evaluation and Research (CBER). Scientific considerations in demonstrating biosimilarity to a reference product: guidance for industry. Retrieved from: http://www.fda.gov/ downloads/DrugsGuidanceComplianceRegulatoryIn formation/Guidances/UCM291128.pdf. Accessed April 2015.

13. US Food and Drug Administration. 2016 Advisory Committee Tentative Meetings. Retrieved from: http://www.fda.gov/AdvisoryCommittees/Calendar/ ucm414515.htm. Accessed 15 Aug 2016.

14. Schiestl M, Stangler T, Torella $C$, et al. Acceptable changes in quality attributes of glycosylated biopharmaceuticals. Nature Biotech. 2011;29:310-2.

15. US Food and Drug Administration. Title VIIimproving access to innovative medical therapies. Retrieved from: http://www.fda.gov/downloads/ Drugs/GuidanceComplianceRegulatoryInformation/ ucm216146.pdf. Accessed 15 Aug 2016.

16. Biosimilars Forum. Frequently asked questions. Retrieved from: http://www.biosimilarsforum.org/ sites/default/files/uploads/biosimilars_faqs_032816 opt_0.pdf. Accessed 28 March 2016 